\title{
Defining Medical Basic Science: General Internists' Special Role in the Reformation of Medical School Education
}

\author{
Elizabeth A. Jacobs, MD, MPP and Adina Kalet, MD, MPH ${ }^{2}$ \\ ${ }^{1}$ Stroger Hospital of Cook County \& Rush University Medical Center, Chicago, IL, USA; ${ }^{2}$ New York University School of Medicine, New York, NY, USA.
}

J Gen Intern Med 24(11):1261-2

DOI: $10.1007 / \mathrm{s} 11606-009-1111-9$

( ) Society of General Internal Medicine 2009

A $\mathrm{s}$ general internists we have a special role to play in the current efforts to reform how basic sciences are incorporated into medical education. The articles by Brass $^{1}$ and Fincher and colleagues ${ }^{2}$ highlight the major points of view in the current debate over how best to restructure medical education to incorporate an ever-expanding scientific knowledge base and better prepare future physicians to practice in a rapidly changing health care delivery landscape. Brass takes the provocative view that the focus on basic sciences in medical education has become fuzzy, to the detriment of medical education and the recruitment of internists and physician scientists; he fears that the proposed changes to the structure of the pre-clinical curriculum threatens the quality of medical education, the physicians it trains, and the future of internal medicine. He warns that if not addressed, this trend away from formal teaching of basic science will make the field of internal medicine less attractive to medical graduates. Fincher and colleagues agree with the premise that basic sciences are important to the training of physicians, but that given the complexity of medical knowledge and practice, call on us to reconsider what constitutes these foundational medical sciences and ensure that we teach them as they will be practiced, in the context of clinical problem solving.

We agree with both and argue that as general internists we are in the unique position to define and advocate for best basic medical science educational practices as the foundation for excellent medical practice.

\section{THE FUTURE OF TEACHING BASIC MEDICAL SCIENCE}

While Brass and Fincher and colleagues agree that basic medical sciences are critical foundational knowledge, they differ on how this material should be taught. Brass expresses the fear of many scientist-educators that teaching the basic sciences within the context of clinical reasoning and without the guide of physician scientists will result in a continued devaluation of the sciences by students. Brass points out that since there is no evidence to support the relative superiority of the past, current, or proposed methods of teaching the basic sciences there is no reason to dismiss the systematic and

Published online September 18, 2009 uniform teaching guidelines developed over one hundred years ago based on Flexner's recommendations ${ }^{3}$. On the face of it, this argument is difficult to sustain in the wake of the dramatic changes in medical knowledge, practice, and the make-up of medical school faculty since the time of Flexner. As Fincher and colleagues point out, these major shifts require a thoughtful but dramatic change in how we prepare physicians during medical school including pre-requisite requirements. Ironically there is little scientific research to support either argument, with the exception of the consistent finding that students retain little of basic medical sciences as currently taught. ${ }^{4-6}$

If we are going to argue for more effective teaching of medical science, there should be better science to guide educational policy making. SGIM members, passionate about clinical practice, education and steeped in relevant methodological expertise should take the lead to redress this evidence gap. This research should address the fundamental work of redesigning medical education to meet the health care needs of society. The American Association of Medical Colleges in their recent joint report with the Howard Hughes Medical Institute entitled "Scientific Foundations for Future Physicians" 7 has made extensive recommendations for this redesign. They include changing pre-medical course requirements to knowledge requirements in order to broaden the depth of scientific teaching and knowledge pre-medical students have upon entering medical school. The idea being that better prepared medical students will reduce the need to expand upon basic medical science teaching in medical school and allow the medical school focus to shift to applied scientific knowledge in clinical contexts. While Brass and others may perceive the recommended "competency" based teaching in medical school as a threat to teaching the basics, the report makes clear that the overall goal is to shift some of this teaching to the pre-medical years so that the focus on basic science is not lost, just taught at different points in future physicians' education.

\section{GENERAL INTERNISTS AS ADVOCATES FOR THE BASIC SCIENCES}

As evident in Brass's article, general internists are not necessarily the first physician group that comes to mind when seeking advocates for teaching basic medical sciences in the pre-clinical years. But clearly the basic medical sciences are especially important to our work. First, we must be prepared to recognize and address clinical issues that arise in any organ and bodily system. Understanding the underlying biochemical, structural, and/or biophysical abnormality that leads to 
clinical disease in any of those systems is critical to our practice. Second, we are the "thinking" doctors-purveyors of the cognitive services. The core of our work rests on integrating vast quantities of clinical and other relevant information, finding patterns in that data, coming up with a plan of action, and problem solving when the initial approach does not work. Third, it is this complex and fascinating detective work that attracts medical students to internal medicine in the face of the allure of other specialties.

Because of the nature of our work, general internists also have special insight into how to balance the "foundational" basic sciences with other "foundational" knowledge. While we agree with Dr. Brass that the basic sciences are part of the foundation of medical education and practicing physicians' practice, we also agree with Dr. Fincher and her colleagues that there are other many important areas of knowledge that constitute this foundation including how to communicate with patients, how to evaluate the medical literature and apply new knowledge to the care of individual patients, understanding the social context of illness, and much more.

\section{CALL FOR COLLABORATION}

Fincher and colleagues outline a way forward in their manuscript stating that "Foundational science and clinical medicine must be integrated inextricably...." While internists, especially general internists, are in a unique position to help guide the integration of this learning, they should collaborate with clinician-scientists. Just like understanding the myriad of factors (social, psychological, biological, etc) that can contribute to an illness is important to being an excellent clinician, it is important that educational reformers understand the viewpoints of those who are expert in the understanding and teaching of the foundational sciences. Not only will this decrease the likelihood that educational reform would negatively impact the teaching of the basic sciences, as Dr. Brass worries, but it will provide the opportunity for clinicianscientists and other medical educators to recognize the expertise and value each brings to the table.
Change is hard, and yet change is needed. The challenge facing us is how to both preserve the essential scientific nature of our profession while facing the ever expanding demands on our time, attention, energy and capacity. Addressing this challenge in medical education will require tremendous creativity and the input of all the stake holders. Dr. Brass expresses a sense of grief for a loss that is very real. Internal medicine is attracting fewer of the "best and the brightest," and the working basic scientific knowledge of our trainees is poor given the time currently committed to teaching science in medical school. However, as Dr. Fincher and colleagues point out, the cause of that loss may very well be the resistance of medical education to powerful evolutionary forces. Our society invests heavily in the training of physicians, and we deserve to benefit fully from this investment. General internists should play a prominent role in attracting medical students to internal medicine, innovating in education, and nurturing our future colleagues and producing the translational research that brings basic science to clinical and educational practice.

Corresponding Author: Elizabeth A. Jacobs, MD, MPP; Stroger Hospital of Cook County \& Rush University Medical Center, 1900 W Polk Street, 16th Floor, Chicago, IL 60612, USA (e-mail: ejacobs@rush.edu).

\section{REFERENCES}

1. Brass EP. Basic biomedical sciences and the future of medical education: implications for internal medicine. J Int Med. 2009. doi:10.1007/s11606009-0998-5.

2. Fincher ME, Wallach PM, Richardson WS. Basic science right, not basic science lite: medical education at a crossroad. J Int Med. 2009 doi:10.1007/s11606-009-1109-3.

3. Flexner A. Medical Education in the United States and Canada. New York: Carnegie Foundation; 1910.

4. Watt ME. Retention of preclinical knowledge by clinical students. Med Educ. 1987;21:119-24

5. Sissons JC, Swartz RD, Wolf FM. Learning, retention, and recall of clinical information. Med Educ. 1992;26:454-61.

6. Swanson DB, Case SM, Luecht RM, Dillon GF. Retention of basic science information by fourth year medical students. Acad Med. 1996:71:S80-2.

7. Report of the AAMC-HHMI Committee. Scientific Foundations for Future Physicians. Association of American Medical Colleges. 2009. 